\title{
Glycemic excursions in diabetic kidney disease: comparison of three therapeutic arms
}

\section{Abstract}

Objectives/Aim of study: To assess the magnitude of glycemic variability (based on blood glucose levels) over 72hours in patients with underlying diabetic kidney disease and $\mathrm{HbAlc}<8 \%$, and to compare the effects of glimepiride, vildagliptin and insulin on glycemic variability.

Materials and Methods: Thirty patients of T2 DM and diabetic kidney disease were chosen whose $\mathrm{HbA1C}$ was less than $8 \%$, fasting plasma glucose less than $150 \mathrm{mg} / \mathrm{dL}$, two hour post prandial plasma glucose less than $200 \mathrm{mg}$ $\mathrm{dl}$, eGFR- between 15 to $59 \mathrm{ml} / \mathrm{min} / 1.73 \mathrm{~m}^{2}$. Exclusion criteria were pregnancy, pre-existing non diabetic kidney disease, decompensated heart failure, liver failure and systemic infections. Patients were categorized into three groups:on glimepiride $(\mathrm{n}=10)$,on vildagliptin $(\mathrm{n}=10)$ and on basal bolus insulin $(\mathrm{n}=10)$. Medications were adjusted to patients' renal function. Patients were managed for their diabetes following the most recent ADA guidelines. Patients underwent CGM for 72 hours and the results were analyzed.

Results: Post dinner capillary blood glucose ( $\mathrm{CBG}$ ) was found to be significantly higher in the glimepiride $(228 \mathrm{mg} / \mathrm{dl} \pm 37.66)$ cohort than vildagliptin $(196 \mathrm{mg} / \mathrm{dl} \pm 40.43)$ cohort $(\mathrm{p}=0.043)$ and the predinner $\mathrm{CBG}$ was significantly higher in the insulin $(130 \mathrm{mg} / \mathrm{dl} \pm 45.08)$ cohort than vildagliptin $(92.89 \mathrm{mg} / \mathrm{dl} \pm 26.06)$ cohort $(\mathrm{p}=0.047)$. No significant difference in daytime as well as nocturnal hypoglycemia was noted among the three arms.

Conclusion: CGMS can reveal episodes of glycemic instability in a diabetic patient categorized as having stable glycemia by HbAlc, FPG and PPPG. Insulin, Glimepiride and Vildagliptin did not differ markedly in reducing
Volume 6 Issue I - 2018

\author{
Kaustubh Chattopadhyay, Pranab Kumar \\ Sahana, Arjun Baidya, Soumik Goswami, \\ Krishna Shankar Gopal Sankar, Nilanjan \\ Sengupta \\ Department of Endocrinology, Nil Ratan Sircar Medical College, \\ India
}

Correspondence: Kaustubh Chattopadhyay, Senior Resident, Department of Endocrinology, Nil Ratan Sircar Medical College, 138,A.J.C Bose Road Kolkata, 7000 I4, India, Tel, 9831510538 , Email:dockaustubh@gmail.com

Received: March 09, 2017 | Published: January 23, 2018

glycemic variability in our study. Strict implementation of lifestyle modification and glycemic control can influence the extent of glycemic variability, which may have influenced the results. Small sample size was also a limiting factor in our study. However, rational and judicious use of antidiabetic medications may help in reducing glycemic variability and hypoglycemic episodes, even in diabetic kidney disease.

Keywords: glycemic variability, diabetic kidney disease
Abbreviations: $\mathrm{CBG}$, capillary blood glucose; GV, glycemic variability; DKD, diabetic kidney disease

\section{Introduction}

The objective of optimal diabetes control is to maintain normal glycated hemoglobin (HbAlc) level in order to prevent diabetic complications. There is considerable evidence from landmark studies that $\mathrm{HbA} 1 \mathrm{c}$ is linked to vascular complications of diabetes. ${ }^{1,2}$ But $\mathrm{HbA1c}$ has its limitations too. Though being representative of an overall glycemic status, yet when incorporting all the components of glycemia, including fasting, preprandial and postprandial hyperglycemia, $\mathrm{HbAlc}$ level does not reflect their relative contribution towards glycemic control. ${ }^{3}$ Moreover, $\mathrm{HbA} 1 \mathrm{c}$ fails to capture glucose fluctuations and does not track glycemic excursions and $60 \%$ of these excursions are not revealed by SMBG alone.

Glycemic variability $(\mathrm{GV})$ takes into account the glycemic excursions including episodes of hyper and hypoglycemia and is a risk factor for the development of diabetic complications independent from $\mathrm{HbA1c}$. This parameter of glycemic control can be assessed using continuous glucose monitoring (CGM). CGM identifies four times more glucose excursions than SMBG and is an upcoming area of research in the field of endocrinology. Lin et al showed annual FPG and $\mathrm{HbA} 1 \mathrm{c}$ variability had a strong association with diabetic kidney disease in type 2 diabetes and impairment of renal function can affect the normal blood glucose metabolism. ${ }^{4}$ So there is great clinical value of CGM in this population of patients. Moreover, patients with diabetic kidney disease (DKD) are more prone to hypoglycemic episodes which can be revealed by CGM.
There are conflicting reports regarding the effect of different antidiabetic agents on glycemic variability in Type $2 \mathrm{DM}$. Hypotheses have been made regarding the superiority of one agent over another on the basis of various studies, including some head to head comparisons..$^{5-7}$ Of particular interest in this respect have been the various insulin regimens and sulfonylureas. Also remarkable are the various DPP4 inhibitor agents, particularly in the context of the recent upsurge in their usage in clinical practice. A number of clinical trials have been done to prove the superiority of one agent over another as well as the superiority of DPP4 inhibitors over other antidiabetic agents. ${ }^{8}$ Our study aims to evaluate the extent of glycemic excursions in diabetic kidney disease in patients with $\mathrm{HbAlc}<8 \%$ and to make a comparative evaluation among the effects of glimepiride, vildagliptin and insulin on glycemic variability. Most of the studies done so far have been head to head comparison of two antidiabetic agents. ${ }^{9} 10$ This study is unique in this aspect, evaluating and comparing the effects of three antidiabetic agents on glycemic variability in a relatively delicate group of patients with underlying diabetic kidney disease.

\section{Materials and methods}

This was a cross sectional study of patients with T2DM complicated by diabetic kidney disease (DKD) treated at Department of Endocrinology, Nilratan Sircar Medical College, Kolkata. The study was approved by the Institutional Ethical Committee and informed consent was obtained from all the study subjects. All patients received an explanation of the procedure and possible disadvantages of participating in the study. Thirty patients with T2 $\mathrm{DM}$ and assumed to have diabetic kidney disease were chosen based 
on $\mathrm{HbA} 1 \mathrm{C}<8 \%$, fasting plasma glucose less than $150 \mathrm{mg} / \mathrm{dL}$, two hour post prandial plasma glucose less than $200 \mathrm{mg} / \mathrm{dl}$, eGFR- between 15 to $59 \mathrm{ml} / \mathrm{min} / 1.73 \mathrm{~m}^{2}$. Patients were categorized into three groups, on glimepiride $(\mathrm{n}=10)$, on vildagliptin $(\mathrm{n}=10)$ and on basal bolus insulin $(\mathrm{n}=10)$ as a unique antidiabetic medication regimen. Medications were adjusted based on renal function, and titrated for goal glucose levels as dictated by the 2016ADA guidelines.

IPro2 CGM system (Medtronic) was used in this study. IPro2 digital recorder, MMT -7741 was used to collect and store data from a glucose sensor and was uploaded into CareLink iPro Therapy Management Software for Diabetes (CareLink iPro, MMT-7340) to generate reports. The IPro2 Docking station charges the iPro 2 and uploads data from iPro2 to CareLink iPro. The iPro2 digital recorder is intended to continuously record interstitial glucose levels in persons with diabetes mellitus and the information is intended to supplement the blood glucose information obtained using standard home glucose monitoring devices. The information collected by the IPro2 digital recorder was uploaded to a computer (with internet access) and reviewed..$^{11-13}$

The study was conducted inpatient. All the patients participating in this study were admitted to NRS Medical College, Kolkata beforehand to ensure proper compliance to medications and to BG monitoring. All the patients were through a patient instruction sheet to complete at least seven blood glucose readings per day in order to avoid data gap, including one blood glucose testing 1 hour after the iPro 2 is connected to the sensor. The patients were told that blood glucose meter readings are required to calibrate the sensor data. The sensors were inserted in the abdomen after cleaning the insertion site with alcohol and allowed to air dry. Patients continued with their normal activities and a log sheet was maintained recording the meals, blood glucose, exercise and medications. The same glucose meter and same lots of strips were used for the entire study. Patients receiving insulin were asked to inject it at least $7.5 \mathrm{~cm}$ away from the sensor insertion site. The iPro2 were covered with Enlite sensor adhesive tab and it was ensured that the sensor fits firmly but comfortably to the insertion site. Patients underwent CGM for 72 hours and results were analyzed.

\section{Statistical method}

Statistical tests used included the Kruskal-Wallis test with multiple comparison post-hoc bonferroni test, post-hoc multiple comparison Tukey's test, Ryan-Einot-Gabriel-Welsh multiple range test and Anova with post-hoc Bonferroni test.

\section{Results}

\section{Patient characteristics}

The baseline characteristics of the patients in three groups are shown in Table 1. Other than age and lipid status, the baseline variables were equivalent in both groups.

Table I Patient Characteristics

\begin{tabular}{|c|c|c|c|c|c|c|c|c|c|c|}
\hline & \multicolumn{3}{|c|}{$\begin{array}{l}\text { Glimepiride, N=I0 } \\
\text { Group I }\end{array}$} & \multicolumn{3}{|c|}{$\begin{array}{l}\text { Insulin, } \mathbf{N}=10 \\
\text { Group } 2\end{array}$} & \multicolumn{3}{|c|}{$\begin{array}{l}\text { DPP4 Inhibitor, N=10 } \\
\text { Group } 3\end{array}$} & \multirow[b]{2}{*}{$\mathbf{P}$} \\
\hline & $\begin{array}{l}\frac{5}{\sigma} \\
\frac{\pi}{\delta} \\
\frac{\pi}{\Sigma}\end{array}$ & 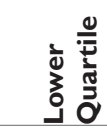 & 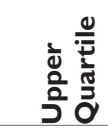 & $\begin{array}{l}\frac{\sigma}{\sigma} \\
\frac{\pi}{\sigma} \\
\Sigma\end{array}$ & دَّ & 吾 & $\begin{array}{l}\frac{\sigma}{\pi} \\
\frac{\pi}{\pi} \\
\frac{0}{\Sigma}\end{array}$ & 岂 & 离 & \\
\hline AGE & 53.5 & 51 & 60 & 54 & 50 & 63 & 62.5 & 57 & 63 & $b, c$ \\
\hline $\begin{array}{l}\text { DM } \\
\text { DURATION }\end{array}$ & 20 & 19 & 22 & 18 & 17 & 21 & 19 & 16 & 23 & ns \\
\hline BMI & 25.6 & 23.6 & 29.9 & 26.9 & 26.5 & 29 & 26.25 & 24.4 & 28.6 & ns \\
\hline AIC & 6.8 & 6.6 & 7 & 7.6 & 7.3 & 7.9 & 7.35 & 6.5 & 7.8 & ns \\
\hline SBP & 148 & 146 & 176 & 155 & 142 & 164 & 132 & 132 & 158 & ns \\
\hline DBP & 80 & 68 & 88 & 86 & 80 & 88 & 75 & 70 & 86 & ns \\
\hline TG & 165 & 146 & 218 & 183 & 134 & 186 & 142 & 122 & 190 & ns \\
\hline LDL-C & 112 & 96 & 118 & 127 & 122 & 152 & 98 & 86 & 112 & $a, c$ \\
\hline HDL-C & 51 & 38 & 54 & 58.5 & 55 & 63 & 35 & 30 & 48 & $a, c$ \\
\hline Creatinine & 2.85 & 1.9 & 3.5 & 2.8 & 2.5 & 3.1 & 2.45 & 2 & 3.1 & ns \\
\hline Egfr & 25.06 & 22.34 & 34.05 & 25.485 & 18.91 & 33.58 & 32.575 & 24.87 & 39.46 & ns \\
\hline Urine ACR & 387 & 256 & 502 & 199 & 42 & 542 & 488 & 310 & 732 & ns \\
\hline $\begin{array}{l}\text { BASELINE } \\
\text { FPG }\end{array}$ & 103 & 82 & 132 & 99 & 92 & 111 & 115.5 & 98 & 122 & ns \\
\hline $\begin{array}{l}\text { BASELINE } \\
\text { PPG }\end{array}$ & 148 & 122 & 164 & 156.5 & 146 & 176 & 158 & 126 & 170 & ns \\
\hline
\end{tabular}

a-significant difference between group I\&2, b-significant difference between group I\&3, c- significant difference between group $3 \& 2$, $p<0.05$ considered as statistically significant, $\mathrm{p}$ values computed by Kruskal-Wallis test with multiple comparison post-hoc bonferroni test and post-hoc multiple comparison Tukey's test and Ryan-Einot-Gabriel-Welsh multiple range test. 


\section{CGM Values}

Comparison among three therapeutic arms: The 24-hour glycemic results are shown in Table $2 \mathrm{~A} \&$ Table $2 \mathrm{~B}$. The mean blood glucose as well as the highest and lowest blood glucose levels within 2 hours before and after each major meal was noted to look into the preprandial and post prandial glycemic excursions. Then the preprandial and postprandial percentages of time the blood glucose levels were above $140 \mathrm{mg} / \mathrm{dl}$ and below $70 \mathrm{mg} / \mathrm{dl}$, respectively were analyzed and compared. An important area in the interpretation of glycemic variability involves the nocturnal glycemic status, so several parameters were analyzed in the nocturnal period between
12 midnight and $6 \mathrm{AM}$ in the morning, including the mean blood glucose and percentages of time the blood glucose levels were above $140 \mathrm{mg} / \mathrm{dl}$ and below $70 \mathrm{mg} / \mathrm{dl}$ in the night. To get a more detailed description of the nocturnal glycemic profile, the nocturnal time span was divided into two halves-12 midnight to $3 \mathrm{AM}$ (early) and 3AM to 6AM (late) and the highest and lowest recorded blood glucose levels in these periods were analyzed and the data from the three arms were compared. In addition, the overall (over 72 hours) mean blood glucose levels and overall percentages of time the blood glucose levels were above $140 \mathrm{mg} / \mathrm{dl}$ and below $70 \mathrm{mg} / \mathrm{dl}$ were taken into account and the measures were statistically analyzed.

Table 2A Comparison of glycemic parameters among three therapeutic arms

\begin{tabular}{|c|c|c|c|c|c|c|c|c|c|c|}
\hline \multirow[b]{2}{*}{ Glycemic Parameters } & \multicolumn{3}{|c|}{ Glimepiride, $N=10$} & \multicolumn{3}{|c|}{ Insulin, N= I 0} & \multicolumn{4}{|c|}{ Vildagliptin, $\mathbf{N}=10$} \\
\hline & & o & $\stackrel{\text { o }}{\supset}$ & $\frac{\Sigma}{\frac{\sigma}{\sigma}}$ & o & $\stackrel{\text { O }}{\supset}$ & $\frac{\sigma}{\frac{\pi}{\pi}}$ & O & $\stackrel{\text { O }}{\supset}$ & $\frac{0}{\frac{0}{\pi}}$ \\
\hline MEAN GLUCOSE IN CGMS & 114 & 99 & 126 & 122 & 99 & 145 & 120.5 & 110 & 156 & NS \\
\hline$\%$ OF TIME BG> 140 & 13.5 & 7 & 18 & 15.5 & 12 & 21 & 14.5 & 9 & 22 & NS \\
\hline$\%$ OF TIME BG <70 & 2.5 & 0 & 4 & 2 & 2 & 4 & 2 & 0 & 5 & NS \\
\hline POST BF MEAN BG & 119 & 113 & 143 & 131 & 117 & 140 & 121 & 118 & 132 & NS \\
\hline POST BF \% OF TIME > I40 & I & I & 2 & I & I & 3 & 2 & 1 & 5 & NS \\
\hline POST BF \% TIME $<70$ & I & 0 & 3 & I & 0 & 4 & 0 & 0 & 1 & NS \\
\hline POST LUNCH MEAN BG & 143 & 121 & 160 & 131 & 117 & 145 & 132.5 & 120 & 142 & NS \\
\hline $\begin{array}{l}\text { POST LUNCH \% OF } \\
\text { TIME > I } 40\end{array}$ & 2 & I & 3 & I & 0 & 3 & 2.5 & 1 & 4 & NS \\
\hline POST LUNCH \% TIME<70 & 1 & 0 & 2 & 1 & 0 & 2 & 0 & 0 & 0 & NS \\
\hline POST DINNER MEAN BG & 150 & 134 & 160 & 135 & 128 & 145 & $|3|$ & 116 & 146 & NS \\
\hline POST DINNER \% OF TIME > I40 & 1 & 0 & 2 & 0.5 & 0 & 2 & 1 & 1 & 3 & NS \\
\hline POST DINNER \% TIME<70 & I & 0 & 2 & I & 1 & 2 & 0 & 0 & 1 & NS \\
\hline NOCTURNAL MEAN BG & 121 & 116 & 127 & 124.5 & 118 & 134 & 121.5 & 110 & 132 & NS \\
\hline NOCTURNAL \% OFTIME > I40 & 11.5 & 10 & 19 & 19.5 & 14 & 23 & 23 & 11 & 23 & NS \\
\hline NOCTURNAL \% OF TIME <70 & 0 & 0 & 8 & I & 0 & 5 & 0 & 0 & 10 & NS \\
\hline
\end{tabular}

a-significant difference between group I\&2, b-significant difference between group I\&3, c- significant difference between group $3 \& 2$, $p<0.05$ considered as statistically significant, a-significant difference between group 1\&2, b-significant difference between group 1\&3, c- significant difference between group $3 \& 2$, $\mathrm{p}<0.05$ considered as statistically significant, $\mathrm{p}$ values computed by Kruskal-Wallis test with multiple comparison post-hoc bonferroni test and post-hoc multiple comparison Tukey's test and Ryan-Einot-Gabriel-Welsh multiple range test. 
Table 2B Comparison of glycemic parameters among three therapeutic arms

\begin{tabular}{|c|c|c|c|c|c|c|c|}
\hline \multirow{2}{*}{ Parameters } & \multicolumn{2}{|c|}{ Insulin, $\mathbf{N}=10$} & \multicolumn{2}{|c|}{ Vildagliptin, $\mathbf{N}=10$} & \multicolumn{2}{|c|}{ Glimepride, $\mathbf{N}=10$} & \multirow{2}{*}{$\mathbf{P}$} \\
\hline & Mean & SD & Mean & SD & Mean & SD & \\
\hline Highest CBG After BF & 228.10 & 47.93 & 232.20 & 53.79 & 230.10 & 48.59 & NS \\
\hline Lowest CBG Before BF & 91.50 & 40.69 & 96.00 & 33.15 & 93.00 & 43.01 & NS \\
\hline Lowest CBG After BF & 126.90 & 45.48 & 111.10 & 39.27 & $\mathrm{II} 5.80$ & 31.45 & NS \\
\hline Highest CBG Before Lunch & 175.90 & 50.37 & 197.40 & 54.62 & 189.10 & 47.66 & NS \\
\hline Highest CBG After Lunch & 209.60 & 34.35 & 222.60 & 44.73 & 232.60 & 38.80 & NS \\
\hline Lowest CBG Before Lunch & 131.80 & 49.45 & 97.10 & 32.27 & 114.40 & 63.94 & NS \\
\hline Highest CBG After Dinner & 209.44 & 40.78 & 196.00 & 40.43 & 228.56 & 37.66 & c- 0.043 \\
\hline Lowest CBG Before Dinner & 130.44 & 45.08 & 92.89 & 26.06 & 115.00 & 41.98 & $a-0.047$ \\
\hline Lowest CBG After Dinner & 132.70 & 29.82 & 118.33 & 24.14 & 127.89 & 33.26 & NS \\
\hline Early Nocturnal Highest CBG & 189.22 & 24.23 & 168.22 & 30.24 & 187.22 & 36.70 & NS \\
\hline Early Nocturnal Lowest CBG & 91.78 & 28.64 & 99.33 & 20.44 & 91.00 & 38.59 & NS \\
\hline Late Nocturnal Highest CBG & 170.89 & 45.80 & 162.33 & 42.20 & 199.11 & 68.41 & NS \\
\hline Late Nocturnal Lowest CBG & 73.11 & 20.59 & 82.67 & 23.00 & 100.00 & 45.44 & NS \\
\hline No Of Symptomatic Hypo & 0.89 & 0.17 & 0.33 & 0.11 & 0.343 & 0.21 & NS \\
\hline No Of Asymptomatic Hypo & 0.89 & 0.33 & 0.67 & 0.27 & I.II & 0.35 & NS \\
\hline
\end{tabular}

$\mathrm{p}<0.05$ considered as statistically significant as computed by ANOVA with post-hoc Bonferroni test, a-significant difference between insulin \& vildagliptin, b-significant difference between insulin \& glimepiride, c-significant difference between glimepiride \& vildagliptin, NS - no significant difference between three groups.

One of the important areas where CGMS is undoubtedly unique is in providing a dependable picture of nocturnal glycemic status, particularly detecting previously unrecognized hypoglycemic events, both symptomatic as well as asymptomatic. Hypoglycemic troughs in the CGMS curve of each patient were identified and retrospectively labeled as symptomatic or asymptomatic based on a validated questionnaire on the symptoms of hypoglycemia and the number of events between the subjects receiving glimepiride, vildagliptin and basal-bolus insulin was compared. The percentages of time the blood glucose level was below $70 \mathrm{mg} / \mathrm{dl}$ between 12 midnight and $6 \mathrm{AM}$ as well as the early (12midnight to $3 \mathrm{AM})$ and late (3AM to $6 \mathrm{AM})$ nocturnal lowest blood glucose values were also analyzed as they were representative of night time hypoglycemia.

Post dinner CBG was found to be significantly higher in the glimepiride (228 \pm 37.66$)$ cohort than vildagliptin (196 \pm 40.43$)$ cohort $(\mathrm{p}=0.043)$ and the predinner $\mathrm{CBG}$ was significantly higher in the

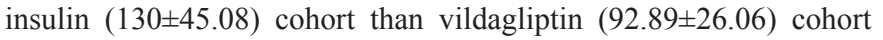
$(\mathrm{p}=0.047)$. No significant difference in daytime as well as nocturnal hypoglycemia was noted among the three arms. Other parameters did not reach a statistical significance in this study, though a numerical difference in the study parameters was found between the three groups.

\section{Discussion}

The management of type 2 diabetes has expanded in a large manner, initially centered around the holy trinity concept (fasting, postprandial blood glucose and $\mathrm{HbA} 1 \mathrm{c}$ ) and then including glycemic variability as a part of the glucose pentad. ${ }^{14} \mathrm{HbA} 1 \mathrm{c}$ does not track glycemic excursions and $60 \%$ of these excursions are not revealed by SMBG alone, whereas continuous glucose monitors identifies four times more glucose excursions than SMBG alone. Glycemic variability is thus a HbAlc independent risk factor for the development of diabetic complications. ${ }^{15,16} \mathrm{GV}$ is another sign of dysglycaemia and according to the recent clinical studies; GV is a significant predictor of mortality in T2DM. ${ }^{17,18}$ The continuous interstitial glucose monitoring systems (CGMS) can detect unrecognized hypoglycemia ${ }^{19}$ and other patterns that may require insulin dose adjustment, that is not detected with intermittent blood glucose monitoring. ${ }^{20,21}$ Early uncontrolled studie $^{22,23}$ and cross-over trials ${ }^{24}$ have shown benefit of using CGMS devices in stabilizing glycemic control. Randomized controlled trials done in diabetic populations, particularly in pregnant women with diabete $^{25}$ and in uncontrolled type 1 diabetes ${ }^{26}$ have recently thrown more light on this subject. The number of patients with diabetic kidney disease has gradually increased over the past decade and type 2 diabetic patients with end-stage renal disease (ESRD) are an emerging threat to prevailing health care system..$^{27,28}$ Diabetic patients have a 
high mortality rate, mainly attributed to cardiovascular disease which is particularly marked in diabetic patients with renal impairment. ${ }^{29}$ The physiology of insulin and glycemia differs markedly in diabetic patients with kidney disease from other diabetic subjects and that these patients are prone to hypoglycemia has been a matter of great clinical concern, particularly posing a problem for treating them with insulin and insulin secretagogues. There are conflicting reports of DPP4 inhibitors doing better than insulin and insulin secretagogues in terms of reducing glycemic excursions, with better long term prospects of reducing diabetic complications. ${ }^{30}$ But very few studies are there involving subjects with diabetic kidney disease. The objective of the present study was to evaluate the clinical performance of a CGMS in type 2 diabetic patients with kidney disease and it is a pilot study comparing the effects of three antidiabetic agents simultaneously on glycemic excursions, all the agents being particularly relevant in the context of modern day diabetes management.

Although a high incidence of unrecognized hypoglycemias has been detected using the CGMS in patients with type 1 diabetes, ${ }^{31}$ extensive information about these events in type 2 diabetic subjects is not available. A recently published article on hypoglycemia and diabetes describes the presence of nondetected hypoglycemias in type 2 diabetic subjects, but only in those with a very long diabetes duration and final insulin deficiency. ${ }^{32}$ In the present study group of type 2 diabetic subjects, the diabetes duration was not very long, and it did not demonstrate a high incidence of this event in type 2 diabetic patients.

Various antidiabetic agents have different effect on glycemic variability in patients with type 2 diabetes and most of the trials have compared between two agents. In this study the effect of vildagliptin, glimepiride and basal bolus insulin on glucose oscillations were compared, basal bolus insulin being closest to the physiological hormonal milieu and the other two agents having predominant post prandial activity. The glycemic parameters analyzed in this study did not show a statistically significant difference between the three agents, though a numerical difference was found. Logically glimepiride should cause less GV among sulfonylureas that is attributed to the extra pancreatic effect, rapid association and dissociation and effect on both phases of insulin secretion in patients with type 2 diabetes. ${ }^{33}$ The insulin-releasing activity has been shown to be low with glimeperide, relative to other sulfonylureas in different studies. ${ }^{34}$ Vildagliptin and other DPP-IV inhibitors increase endogenous GIP and GLP-1 by inhibiting their degradation. In the study by Yiwen Qiu et al., ${ }^{35}$ they concluded that in T2DM patients with DKD, blood glucose fluctuation is an important factor affecting their survival rate and vildagliptin can reduce blood glucose fluctuation in this subset of patients. In another study looking into the efficacy of vildagliptin on glucose fluctuation in Japanese patients, it was concluded that vildagliptin when added to ongoing SU based OHA therapy for 12 weeks significantly improved glycemic fluctuation as well as glycemic control in Japanese patients with T2DM. ${ }^{36}$ In another head to head comparative study between vildagliptin and glimepiride, it was revealed that Vildagliptin treatment was associated with less fluctuation of glucose levels than glimepiride treatment as assessed by 24-h CGM device, suggesting vildagliptin may have the potential to offer long-term beneficial effects for patients with T2DM in preventing the development of complications of diabetes. ${ }^{37}$ Several reports show DPP-4 inhibitors are non-inferior to insulin secretagogues in terms of reducing glycemic variability. ${ }^{38,39}$ It is also reported that DPP-4 inhibitors are more efficacious in the
Asians. ${ }^{40}$ But the superiority of vildagliptin and basal bolus insulin over sulfonylureas as claimed in the literature was not supported in the present study.

The small number of patients was a limiting factor in this study. Another factor is the cost of CGMS and this is one of the reasons preventing diabetologists for using it liberally. In the present study, the patients attending this tertiary care hospital mostly belonged to lower socioeconomic status and CGMS could be done only in selected cases. Another limiting factor in this study was that the patients were being closely supervised and kept under strict glycemic control. Although hospital admission is not a prerequisite for performing CGMS, in this study all the patients were admitted prior to CGMS for proper calibration with self monitored blood glucose values and optimum procedural factors during 72 hours of CGMS, most patients being illiterate and lack enough of motivation. The data being collected inpatient may have been a source of bias in this study. Future studies done with a higher number of ambulatory patients may throw more light on this upcoming area of medical research.

\section{Conclusion}

Insulin, Glimepiride and Vildagliptin did not differ markedly in their impact on glycemic variability in DKD subjects in the inpatient setting under carbohydrate restricted diet. Hypoglycemic events (symptomatic as well as asymptomatic) also did not differ significantly in these three arms. Strict implementation of lifestyle modification and optimum glycemic control may have influenced the study results, small sample size being another limiting factor.

\section{Acknowledgment}

None.

\section{Conflicts of interest}

None.

\section{References}

1. The Diabetes Control and Complication Trial Research Group. The effect of intensive treatment of diabetes on the development and progression of long-term complications in insulin-dependent diabetes mellitus. $N$ Engl J Med. 1993;329:977-986.

2. Nathan DM, Cleary PA, Backlund JY, et al. Intensive diabetes treatment and cardiovascular disease in patients with type 1 diabetes. $N$ Engl J Med. 2005;353(25):2643-2653.

3. Monnier L, Lapinski H, Colette C. Contributions of fasting and postprandial plasma glucose increments to the overall diurnal hyperglycemia of type 2 diabetic patients:variations with increasing levels of HbA(1c). Diabetes Care. 2003;26(3):881-885.

4. Lin CC, Chen CC, Chen FN, et al. Risks of diabetic nephropathy with variation in hemoglobin A1c and fasting plasma glucose. Am J Med. 2013;126(11):1017e1-1017e10.

5. Kalra S, Kalra B. The glycemic pentad:Role of insulin analogues. Webmed Central Endocrinology 1:WMC00562, 2010.

6. Celliello A, Davidson J, Hanefeld M, et al. Postprandial hyperglycaemia and cardiovascular complications of diabetes:an update. Nutr Metab Cardiovasc Dis. 2006;16(7):453-456.

7. Desouza CV, Bolli GB, Fonseca V. Hypoglycemia, diabetes, and cardiovascular events. Diabetes Care. 2010;33(6):1389-1394. 
8. Standl E, Schnell O, Ceriello A. Postprandial hyperglycemia and glycemic variability: should we care? Diabetes Care. 2011;34(Suppl 2):S120-S127.

9. Scherbaum WA, Schweizer A, Mari A, et al. Evidence that vildagliptin attenuates deterioration of glycaemic control during 2-year treatment of patients with type 2 diabetes and mild hyperglycemia. Diabetes Obes Metab. 2008;10(11):1114-1124.

10. Ellis SL, Moser EG, Snell-Bergeon JK, et al. Effect of sitagliptin on glucose control in adult patients with type 1 diabetes:A pilot, doubleblind, randomized, cross over trial. Diabet Med. 2011;28(10):1176-1181.

11. Monnier L, Colette C, Owens DR. Glycemic variability:the third component of the dysglycemia in diabetes. Is it important? How to measure it? J Diabetes Sci Techno. 2008;2(6):1094-1100.

12. El-Kebbi IM, Ziemer DC, Cook CB, et al. Utility of casual postprandial glucose levels in type 2 diabetes management. Diabetes Care. 2004;27(2):335-339.

13. Rohlfing CL, Wiedmeyer HS, Little RR, et al. Defining the relationship between plasma glucose and HbA1c. Diabetes Care. 2002;25(2):275278.

14. Coresh J, Selvin E, Stevens LA, et al. Prevalence of chronic kidney disease in the United States. JAMA. 2007;298(17):2038-2047.

15. US Renal Data System. USRDS 2007 Annual Data Report. National Institutes of Health, National Institute of Diabetes and Digestive and Kidney Diseases, USA, Bethesda, 2007.

16. Kimmel PL, Varela MP, Peterson RA, et al. Interdialytic weight gain and survival in hemodialysis patients:effects of duration of ESRD and diabetes mellitus. Kidney Int. 2000;57:1141-1151.

17. Muggeo M, Zoppini G, Bonora E, et al. Fasting plasma glucose variability predicts 10-year survival of type 2 diabetic patients:the Verona Diabetes Study. Diabetes Care. 2000;23(1):45-50.

18. Mellbin LG, Malmberg K, Ryden L, et al. The relationship between glycaemic variability and cardiovascular complications in patients with acute myocardial infarction and type 2 diabetes:a report from the DIGAMI 2 trial. Eur Heart J. 2013;34(5):374-379.

19. Boland E, Monsod T, Delucia M, et al. Limitations of conventional methods of self-monitoring of blood glucose:lessons learned from 3 days of continuous glucose sensing in pediatric patients with type 1 diabetes. Diabetes Care. 2001;24(11):1858-1862.

20. Kaufman FR, Austin J, Neinstein A, et al. Nocturnal hypoglycemia detected with the continuous glucose monitoring system in pediatric patients with type 1 diabetes. J Pediatr. 2002;141(5):625-630.

21. Kaufman FR, Gibson LC, Halvorson M, et al. A pilot study of the continuous glucose monitoring system:clinical decisions and glycemic control after its use in pediatric type 1 diabetic subjects. Diabetes Care. 2001;24(12):2030-2034.

22. Lu H, Castells S, Hagerty D. Study of glucose profiles with continuous glucose monitoring in adolescents with poorly controlled type 2 diabetes mellitus. J Pediatr Endocrinol Meta. 2008;21(8):729-736.

23. Ludvigsson J, Hanas R. Continuous subcutaneous glucose monitoring improved metabolic control in pediatric patients with type 1 diabetes:a controlled crossover study. Pediatrics. 2003;111(5 Pt 1):933-938.

24. Murphy HR, Rayman G, Lewis K, et al. Effectiveness of continuous glucose monitoring in pregnant women with diabetes: randomized clinical trial. BMJ. 2008;337:a1680.

25. Deiss D, Bolinder J, Riveline JP, et al. Improved glycemic control in poorly controlled patients with type 1 diabetes using real-time continuous glucose monitoring. Diabetes Care. 2006;29(12):2730-2732.
26. Tamborlane WV, Beck RW, Bode BW, et al. Continuous glucose monitoring and intensive treatment of type 1 diabetes. $N$ Engl J Med. 2008;359(14):1464-1476.

27. US Renal Data System. USRDS 2007 Annual Data Report. National Institutes of Health, National Institute of Diabetes and Digestive and Kidney Diseases, USA, Bethesda, 2007.

28. Kimmel PL, Varela MP, Peterson RA, et al. Interdialytic weight gain and survival in hemodialysis patients:effects of duration of ESRD and diabetes mellitus. Kidney Int. 2000;57(3):1141-1151.

29. Gaede P, Vedel P, Larsen N, et al. Multifactorial intervention and cardiovascular disease in patients with type 2 diabetes. $N$ Engl J Med. 2003;348(5):383-393.

30. Zhang $\mathrm{H}, \mathrm{Bu} \mathrm{P}, \mathrm{Xie} \mathrm{YH}$, et al. Effect of repaglinide and gliclazide on glycaemic control, early-phase insulin secretion and lipid profiles in. Chin Med J (Engl). 2011;124(2):172-176.

31. Metzger M, Leibowitz G, Wainstein J, et al. Reproducibility of glucose measurements using the glucose sensor. Diabetes Care. 2002;25(7):11851191.

32. Segel SA, Paramore DS, Cryer PE. Hypoglycemia-associated autonomic failure in advanced type 2 diabetes. Diabetes. 2002;51(3):724-733.

33. Davis SN. The role of glimepiride in the effective management of Type 2 diabetes. J Diabetes Complications. 2004;18(6):367-376.

34. Muller G, Satho Y, Geisen K. Extrapancreatic effects of sulfonylureasa comparison between glimepiride and conventional sulfonylureas. Diabetes Res Clin Pract. 1995;28(Suppl 1):S115-S137.

35. Yiwen Qiu, Xiaojun Luan, Jinsong Chen, et al. Effects of vildagliptin on blood glucose fluctuation in patients with end-stage renal disease under hemodialysis in type 2 diabetes mellitus. Int $J$ Clin Exp Med. 2016;9(6):9557-9562.

36. Yoshioka K, Isotani H, Ohashi S, et al. Efficacy of vildagliptin on glucose fluctuation in Japanese type 2 diabetic patients with ongoing sulfonylurea based oral glycemic agent therapy. Diabetes Metab Syndr. 2013;7(1):3234.

37. He YL, Foteinos G, Neelakantham S, et al. Differential effects of vildagliptin and glimepiride on glucose fluctuations in patients with type 2 diabetes mellitus assessed using continuous glucose monitoring. Diabetes, Obesity and Metabolism. 2013;15(12):1111-1119.

38. Nauck MA, Meininger G, Sheng D, et al. Efficacy and safety of the dipeptidyl peptidase-4 inhibitor, sitagliptin, compared with the sulfonylurea, glipizide, in patients with type 2 diabetes inadequately controlled on metformin alone:a randomized, double-blind, noninferiority trial. Diabetes Obes Metab. 2007;9(2):194-205.

39. Goke B, Gallwitz B, Eriksson J, et al. Saxagliptin is non-inferior to glipizide in patients with type 2 diabetes mellitus inadequately controlled on metformin alone:a 52-week randomised controlled trial. Int J Clin Pract. 2010;64(12):1619-1631.

40. Shimoda S, Iwashita S, Ichimori S, et al. Efficacy and safety of sitagliptin as add-on therapy on glycemic control and blood glucose fluctuation in Japanese type 2 diabetes subjects ongoing with multiple daily insulin injections therapy. Endocr J. 2013;60(10):1207-1214.

41. Service FJ, Molnar GD, Rosevear JW, et al. Mean amplitude of glycemic excursions, a measure of diabetic instability. Diabetes. 1970;19(9):644 655 . 